\title{
Implementing poultry vaccination and biosecurity at the village level in Tanzania: a social strategy to promote health in free-range poultry populations
}

\author{
Peter L. M. Msoffe - David Bunn - A. P. Muhairwa - M. M. A. Mtambo • \\ H. Mwamhehe • A. Msago • M. R. S. Mlozi • Carol J. Cardona
}

Accepted: 3 August 2009/Published online: 18 August 2009

(C) The Author(s) 2009. This article is published with open access at Springerlink.com

\begin{abstract}
A social strategy was tested for implementing Newcastle disease (ND) vaccination and biosecurity improvements among free-ranging chicken at village level in Tanzania. In addition to training the local poultry vaccinators, data recorders and poultrykeepers, the strategy involved training and empowering leaders at the district, ward and village level. The trainings covered poultry health, management, and marketing of village chickens, with an emphasis on ND vaccination and improving biosecurity against avian influenza (AI), The study sites included villages in one ward in each of three each three districts (Iringa, Mtwara-Mikindani, and Mvomero) of mainland Tanzania. Ninety-six local leaders at district level and 101 leaders at ward levels were trained. In addition, 196
\end{abstract}

P. L. M. Msoffe $(\varangle) \cdot$ A. P. Muhairwa $\cdot$ M. M. A. Mtambo Department of Veterinary Medicine and Public Health, Sokoine University of Agriculture,

P.O. Box 3021, Chuo Kikuu,

Morogoro, Tanzania

e-mail: makengamsoffe@yahoo.co.uk

D. Bunn

Wildlife Service Center, University of California Davis, One Shields Avenue,

Davis, CA 95616, USA

\section{J. Cardona}

Veterinary Medicine Extension,

University of California Davis,

One Shields Avenue,

Davis, CA 95616, USA farmers (households) were trained, as well as 86 vaccinators and 26 data recorders. Data recorders were also trained as poultry first aid workers. ND vaccination was conducted by the vaccinators, supervised by their local leaders with technical assistance from veterinarians. A total of 158,343 village chickens were vaccinated in three rounds of vaccination three months apart. The training and empowerment of local leaders and local implementers was the key element for success as it fostered the feeling of local ownership of the program and prevented conflicts with other development activities within the villages. We conclude that most animal health programs will increase their odds of success by involving local leaders and by addressing the current challenges facing the

H. Mwamhehe

Ministry of Livestock Development and Fisheries, Southern Highlands Veterinary Investigation Center, P.O. Box 290, Iringa, Tanzania

A. Msago

Wildlife Conservation Society, Ruaha landscape Program, P.O. Box 1654, Iringa, Tanzania

M. R. S. Mlozi

Department of Agricultural education and extension, Sokoine University of Agriculture, P.O. Box 3002, Chuo Kikuu, Morogoro, Tanzania 
farmers. Further assessment on the usefulness of this approach is needed.

Keywords Biosecurity - Community animal health . Newcastle disease Poultry vaccination . Village chicken

\section{Introduction}

Local chickens are an important resource benefiting the livelihoods of impoverished people in developing countries. Household chicken production provides food and income and is an important component of food security for the rural poor. Selling local chickens is one of the few income-generating activities accessible to women in poor households. Local chicken production is a low input system requiring minimal investment to maintain (Branckaert 2007). Even in households without land chickens can be raised, because they can be sustained by allowing them to scavenge for sustenance between houses and on communal village land (Sonaiya 1990; Barua and Yoshimura 1997; Gueye 2000; Kitalyi 1998; Branckaert et al. 2000; Permin et al. 2001).

Rampant poultry diseases, predation, and poor production practices are among hindrances to village poultry productivity (Mwalusanya et al. 2001; Kitalyi 1998). Viscerotropic velogenic Newcastle disease (referred to hereafter as ND) and parasites have been identified as the major health threats to local chickens in sub-Saharan Africa (Kitalyi 1998; Minga et al. 2001). It appears that the ecology of village chickens exposes them to ideal conditions for these health problems (Yongolo 1996; Permin and Hansen 1998). Chickens from multiple households often congregate during scavenging to form one large sub-village or village flock, creating infectious disease exposure and transmission dynamics that are unique among poultry production systems, and where intervention strategies are difficult to apply.

While the human community structure in African villages allows the co-mingling of household flocks, it may also provide the human social setting for collective action to prevent diseases and improve poultry production. In contrast to the social setting in North America, for example, where individual households are not prone to act collectively to improve animal production, village communities in Tanzania routinely act collectively (Mwaikusa 1994; Krishna et al. 1997). The community structure of the rural village setting in Tanzania is conducive to local collective action for implementing a communitybased local poultry program, including a ND vaccination program (Snyder 2008; OECD-DAC 2001).

The Newcastle Disease and Avian Flu Control Project (NDAFC project) was aimed at testing the effectiveness of a multi-level community approach to implement a Newcastle disease vaccination and general poultry health and management program in three districts in Tanzania. We hypothesized that successful intervention for disease control (animal or human) requires: 1) an approach that considers local social, economic, and biological settings; 2) community involvement; 3 ) specific disease control efforts to be part of broader poultry health programs that address the priority diseases as measured by the community, as well as production and marketing problems faced by rural farmers.

\section{Materials and methods}

Program development

Ministry Veterinary Investigation Centres (VIC) veterinarians and Sokoine University of Agriculture veterinary faculty participating in discussion groups of an Avian Flu School course in Tanzania in 2006 (Beltran et al. 2008) concluded that a narrow approach to training in rural communities about biosecurity to prevent avian flu would have very limited success in the existing context of high poultry mortality caused by Newcastle and other conditions (Mwakapuja et al. in press). Thus, workshop participants recommended a more comprehensive training approach that addressed the major sources of poultry mortality in addition to avian influenza. In addition, the workshop group suggested that early engagement with district, ward, and village leaders would make the project more sustainable. After further consultation with other field veterinarians, the Newcastle Disease and Avian Flu Control Research Project was developed to broadly address poultry health, including an ND vaccination program, and an outreach and training strategy that involved local leaders and was integrated with the village community structure. 
Training local social and technical leadership

A community approach made it possible to apply interventions to the whole village poultry flock.

To enlist the community support for this approach, trainings were conducted within the various levels of the community social structure. The social leadership and governance structure at the local level in rural Tanzania is comprised of: 1) districts - the highest local authority composed of several wards; 2) wards a collection of villages and the level at which key local decisions are made; 3 ) villages - a collection of sub-villages usually comprised of 250 households or more; and 4) sub-villages - containing six up to a few hundred households (Fig. 1).

Leadership from district to village levels is composed of both technical staff, who are employed based on their qualifications, and elected leaders. At the district level, the technical team is headed by the district executive director and is composed of experts in charge of agricultural and livestock development, education, economics, and health. District councils are comprised of the elected councillors, appointed women representatives, and district technical team members. This is the highest decision-making body at the district level and is directed by a council chairperson. A similar structure is set for the wards, with the highest authority referred to as the Ward Council (for which members are drawn from the ward and its constituent villages). At village level there is the Village Council, whose members are from the village and constituent sub-villages. At sub-village level the structure is a little different, with only

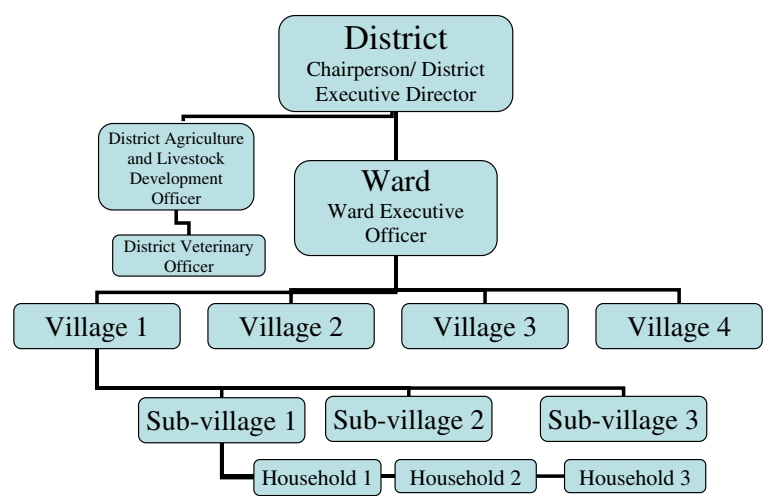

Fig. 1 Chart of organizational relationships of districts, wards, villages and the titles of key leadership at each level such as District Veterinarian elected leaders. The decision-making body is the subvillage meeting, which is open to all households (CLGF 2008).

The trainings for local leaders were focused on two groups: 1) elected leaders, including the district and ward councils and district, village, and sub-village leaders, and 2) technical staff, including the district, ward, and village agriculture and animal health practitioners, community development officers, and education officers, all of whom have direct links to community development and animal health.

The goals for training the local leaders were severalfold. The first goal was to familiarize them with the program so that they could assist project leaders in preventing conflicts with existing development programs for time and resource allocation. Second, their involvement ensured institutional support for future inclusion of ND vaccination and poultry education programs in their village, ward and district plans, hence to set budget and bi-laws to sustain the program into the future. Finally, we sought to solicit views and input from local leaders to ensure the smooth operation of the program.

The trainings were conducted as one-day workshops in the Kiswahili language, with facilitators from the NDAFC Project leading the proceedings. The facilitators consisted of four veterinarians, one social economist with Sokoine University of Agriculture, and a wildlife liaison officer from an international NGO. The training covered the following topics:

1. Benefits of local chicken for food and income. Specifically, the socio-economic aspects of local poultry production, including income potential for households during emergencies, were discussed. A case study on the impact of the number of village chickens transported to the town centres every month was used to exemplify the potential of village chickens in combating poverty (Mlozi et al. 2003).

2. Poultry diseases affecting local chicken flocks. A specific overview of avian influenza virus transmission, prevention, early detection, and its differentiation from ND was included.

3. An overview of local chicken management including egg management, feeding, housing, and marketing.

4. Available support for poultry health and production, including the important role of ministries 
and local government in providing local resources and/or enacting supportive bylaws.

Workshop trainees were selected by local authorities in consultation with the NDAFC Project coordinator and were invited through the relevant office. For district level training, the trainees were invited by the District Executive Director, and for the ward and village-level trainees, the invitation was through the Ward Executive Officer and Village Executive Officers, respectively. The trainings consisted of short lectures and discussions in which facilitators introduced a topic, followed by contributions from the trainees. The trainees were encouraged to ask questions and facilitators responded or asked other trainees to contribute to the response. During village-level training, a group of local artists under the guidance of a professional art director performed a drama on poultry management, health, and marketing. Throughout the workshop, participants at all levels were actively invited to contribute their experiences and difficulties in raising village poultry. Shared experiences of the participants were invaluable to the program. At the end of the course, trainees were asked to put forward their plans of action for implementing the NDAFC Project. Plans were reviewed and discussed.

\section{Training vaccinators}

Following the leaders' training at the ward level, the sub-village chairpersons were asked to nominate vaccination trainees based on their responsibility and trustworthiness. Depending on the size of the subvillage, one to three vaccinators were trained in each, and both males and females were recruited. To implement the ND vaccination program, the nomination of vaccinators was done by the sub-village leadership, which meant that the number of women and men was not determined by project coordinators, but by local leadership. The leaders in the Mzumbe Ward considered the physical nature of the vaccinators' work unsuitable for women because of the longdistance bicycling involved, and therefore nominated only men. To ensure proper supervision of the vaccinators by the local leadership, it was decided that vaccinators should not be drawn from leaders. Vaccinator training was conducted by a team of three veterinarians in Mzumbe and Ufukoni and three veterinarians and a wildlife liaison officer in Mlowa.
All ward vaccinator trainings were organised by the ward leaders, assisted by members of the project team. Trainings were conducted in nearby primary schools, except in Mzumbe ward where the training was held in the ward executive office. The trainees were given $\mathrm{I}_{2} \mathrm{ND}$ vaccine from the NDAFC Project for the first three rounds of vaccination, and thereafter were directed to veterinary supply shops where they could purchase the vaccine. A key aspect of the training was suggesting principles for communicating and engaging with farmers, including communicating with courtesy, being attentive, and ensuring that poultry owners understand why they should vaccinate. Vaccinators were also trained to record the number of chickens present at the time of vaccination, the number of chickens that were vaccinated, and the reasons for not vaccinating some chickens.

Training village households

Selected village households were trained in poultry management, poultry health (including prevention of ND and avian influenza), and poultry marketing. The farmers were selected based on their participation in the project activities. Priority was given to households involved in weekly data collection, and households of vaccinators and data collectors. To increase the number of households trained, each household was limited to one participant. To improve communication, this training was done through a drama that was performed by a local group, rather than by traditional lectures. The local drama group was trained by NDAFC project veterinarians on the basics of village poultry management, poultry health (including disease prevention), and marketing. With assistance from a local professional director, a Kiswahili play was written and performed by the group. The play lasted about 45 minutes, and afterward farmers were encouraged to ask questions of the veterinarians, socio-economist, and the wildlife liaison officers present. Some questions were also posed to the farmers by the drama group director. These drama trainings were conducted in all three project wards with members from all villages congregating in a prescribed centre, usually a local primary school. Project personnel noted that the presence of the drama group seemed to increase participation, drawing in children and non-project farmers who happened to be in the vicinity when they performed. 
Implementing the vaccination of village flocks

Much work has been done to develop and test an ND vaccine which can be used in developing world settings (Alders et al. 2002). One such vaccine, the $\mathrm{I}_{2}$ strain of ND vaccine (hereafter referred to as $\mathrm{I}_{2}$ ) used in this project has been developed as a public access vaccine and is produced by the Tanzania Central Veterinary Laboratory (Wambura et al. 2000). It is distributed via the network of Veterinary Investigation Centres and district veterinarians.

The vaccination effort was implemented similarly in the three project regions of Mtwara, Morogoro, and Iringa. After completing the training of local leaders, vaccinators, and data recorders, the first vaccination was carried out by the vaccinators together with project veterinary experts. Vaccination started between July and September 2007, and data recording on the dynamics in chicken and egg numbers, mortalities and marketing began between December 2007 and January 2008. Social economic data were collected concurrently with the first vaccination. The NDAFC Project purchased $\mathrm{I}_{2}$ vaccine and distributed it to each ward. The vaccinators obtained the vaccine from the Ward Executive Officer (WEO) at no cost. The WEOs supervised the distribution of vaccine and the vaccination activities to settle disputes between the participants, ensure that the vaccine distribution was adequate, and verify that the vaccinators performed their duties adequately. They also collected and stored vaccination records from vaccinators and data collectors before turning them over to the NDAFC Project coordinator. The WEOs supervised the payment of facilitation fees and transport costs to the vaccinators. (Vaccinators were provided cash to rent bicycles and were promised compensation at an equivalent of US\$ 15 each per vaccination period.) The agriculture and livestock extension officers in the ward, community development officers, the education coordinator, village executive officers, and sub-village chairpersons assisted the WEOs with implementation of the vaccination program.

Tracking vaccination outcomes

To ensure that data was collected correctly, a group of data recorders were trained for the project. The data recorders were given similar training as the vaccinators, with an added emphasis on good data collection and reporting. They recorded data from households weekly for six months. The data they collected included numbers of chickens categorized into chicks (0-8 weeks), growers ( 8 weeks 6 months) and adults (over 6 months), number of eggs, reasons for a increase or decrease in numbers, and how chickens and eggs were utilized. Specific data fields are listed in Table 1. The data was collected from a minimum of three randomlyselected households in each sub-village by means of a questionnaire that was completed with the assistance of the head of the household or a representative. Data collectors submitted the completed forms to the project coordinator, who reviewed the data and entered it into a digital database for processing and analysis.

Training village poultry first aid workers

Within six months of the cessation of data collection activities, the project coordinator met with all the data recorders in their wards to collect feedback on the data collection process. During these discussions, it emerged that farmers, after receiving training, asked the recorders questions that could not be answered using the knowledge available to them. This necessitated designing and implementing a supplemental training. The training was conducted at Sokoine

Table 1 Data collected by recorders

\begin{tabular}{ll}
\hline Data category & Specific data fields \\
\hline Chicken numbers & $\begin{array}{l}\text { Number present } \\
\text { Increase from purchase/gifts in }\end{array}$ \\
& $\begin{array}{l}\text { Decrease from death, sales, } \\
\text { gift out, lost }{ }^{\mathrm{a}}\end{array}$ \\
& Chickens sold $^{\text {Total eggs laid }}$ \\
Production numbers & Eggs sold $^{\mathrm{b}}$ \\
& Eggs incubated \\
& Chicks hatched \\
Revenue from all sales & Sick \\
Chicken health & Dead \\
& Description of disease signs \\
\end{tabular}

${ }^{\mathrm{a}}$ These numbers were calculated based on current and previous data.

${ }^{\mathrm{b}}$ Data is a subset of total eggs laid. 
University of Agriculture and participants included data recorders from the three project wards. The training was conducted in Kiswahili by four university-based veterinarians associated with the NDAFC project, and covered three broad topics: 1) identification and control of common chicken diseases; 2) general husbandry for village chickens, and 3) local marketing of chicken products.

The training was conducted in both short lectures and through interactive group work, and differed from that offered to farmers. Its aim was to create a cadre of trainees to assist farmers in the identification of poultry health problems and to promptly report them to extension workers, including sending samples of sick or dead birds. The trainees were also instructed to remind the farmers about important health interventions such as vaccinations and treatment against ectoparasites and worms.

\section{Results}

Project outcomes were measured by 1) assessing the number of people trained as a result of local leadership engagement; 2) the numbers of birds vaccinated for ND; and 3) the change in status of ND in the villages after vaccination.

Results of trainings

\section{Training of district and ward leaders}

A total of 197 leaders at district and ward levels were trained in the importance of village chickens, social and economic aspects of village poultry, an overview of avian influenza and other important poultry diseases, village poultry management, and their role in providing institutional support for the program (Table 2). The trainees included all of the district veterinarians, agricultural extension staff, district councillors, ward education coordinators, ward/village executive officers, village chairpersons, and community development officers. Ninety percent of the invited trainees participated. Of the 197 participants, 67 were women (34\%) (Table 4). Leadership training prevented unnecessary scheduling and resource conflicts between the vaccination program and other local development activities such as building schools in the villages. Following training, leaders at
Table 2 Number of leaders and villagers trained in three Districts participating in the program

\begin{tabular}{llll}
\hline & Total & Female & Male \\
\hline District & & & \\
Iringa & 20 & 6 & 14 \\
Mtwara & 38 & 9 & 29 \\
Mvomero & 38 & 10 & 28 \\
Ward & & & \\
Mlowa & 41 & 10 & 31 \\
Mzumbe & 38 & 17 & 21 \\
Ufukoni & 22 & 15 & 7 \\
\hline
\end{tabular}

the sub-village, village, and ward levels assumed responsibility for ensuring the success of the program. The high number of leaders trained is also likely to positively influence decisions to support future poultry health and production projects as a means of safeguarding human health and improving livelihoods.

\section{Vaccinator and recorder training}

The village and sub-village leaders selected the trainees for both data recording and vaccination.

A total of 86 village chicken vaccinators were trained in three wards: 64 in Mzumbe Ward, 16 in Mlowa Ward, and 6 in Ufukoni Ward (Table 3). Of the 86 vaccinators, $32(37 \%)$ were women. Twentysix data collectors were trained: 14 from Mzumbe and 6 each from Mlowa and Ufukoni (Table 3). Of the 26 data collectors, $6(23 \%)$ were women.

\section{Farmers training}

196 farmers were trained on similar topics as the local leaders, except that the training was presented as a drama, and farmer's questions were answered by project poultry experts (Table 4). A special effort was made to include women farmers in the training. This effort resulted from the desire of the project team and village leaders to enable more women to participate in raising village poultry to ensure more secure livelihoods, financial empowerment of women and to improve their capacity to care for the sick and elderly. However, out of the 196 farmers trained only 78 $(40 \%)$ were women, possibly because men had an 
Table 3 Number of vaccinators, data recorders and first aid workers trained

\begin{tabular}{llllllllll}
\hline Ward & \multicolumn{2}{l}{ Vaccinators } & \multicolumn{3}{c}{ Data recorders } & \multicolumn{3}{c}{ First aid worker } \\
\hline & Total & F & M & Total & F & M & Total & F & M \\
\hline Mlowa & 16 & 4 & 12 & 6 & 1 & 5 & 6 & 1 & 5 \\
Mzumbe & 64 & 25 & 39 & 14 & 2 & 12 & 14 & 2 & 12 \\
Ufukoni & 6 & 3 & 3 & 6 & 3 & 3 & 6 & 3 & 3 \\
Total for all wards & 86 & 32 & 54 & 26 & 6 & 20 & 26 & 6 & 20 \\
\hline
\end{tabular}

upper hand in selecting the participants as most of the village leaders were men. Farmers' training was essential to prepare them for the interaction with the vaccinators and the data recorders. Based on interviews of vaccinators and recorders, there was a significant improvement in their rapport with farmers after the farmers had attended the training. Before that there were incidences where farmers did not welcome the idea of someone else collecting the data about their poultry project or doing vaccination.

\section{Village chicken first aid workers training}

All 26 data recorders from the three wards Mlowa (6), Mzumbe (14) and Ufukoni (6) participated in the poultry basics training. Of these trainees, 7 (27\%) were women.

\section{Results of newcastle disease vaccination program}

Three rounds of vaccination within a one year period were conducted. In total, 158,343 individual birds were vaccinated (Table 5). The control of ND appeared to be effective. A survey conducted before the institution of the vaccination program found that an average of $53.1 \%$ household respondents in the three project wards reported an outbreak of ND in 2006. That number dropped to $15.7 \%$ in December 2007 , after just one round of vaccination. During the

Table 4 Number of villager households trained in three districts participating in the programme

Households trained

\begin{tabular}{llll}
\hline & Total & Female & Male \\
\hline Mlowa & 50 & 18 & 32 \\
Mzumbe & 66 & 19 & 47 \\
Ufukoni & 80 & 41 & 39 \\
\hline
\end{tabular}

data-recording period starting in December 2007, none of the farmers contacted (all 196 trained farmers) reported outbreaks of ND in their flocks, indicating that the program was working. While some chickens were certainly missed during the vaccination efforts, it is expected that some of them became vaccinated and immunized through contact with the vaccinated chickens, since a live vaccine $\left(\mathrm{I}_{2}\right)$ was used.

\section{Discussion}

This project employed both social and technical strategies for implementing a program to improve poultry health. Limited household resources, the collective nature of the villages (Quinn et al. 2007; Msoffe personal communication 2008), the existing local governance structure and systems (OECD-DAC 2001; CLGF 2008), and the ecological reality of freeranging village chickens are the key features of the Tanzania rural setting that all influenced the project design.

Various methods for community-based approaches have been employed in the delivery of human health care for decades. Prevention of rabies, dengue fever and influenza in humans, rehabilitation, neonatal care, and numerous other health issues have been the focus of successful community-based programs (Swaddiwudhipong et al. 1992; Gubler and Clark 1996; Kitala et al. 2000; WHO 2003; Bhutta et al. 2005; Traeger et al. 2006). International conservation programs have also adopted community approaches to protecting biodiversity, particularly through the establishment of community managed protected areas, and sustainable harvest programs for aquatic or forest reserves (Curtin 2002; Banks et al. 2003; Manan and Ibrahim 2003; Bajracharya et al. 2006; Balint 2006). But the application of community-based approaches to animal health is less common. The community-based approach is particularly appropriate in preventing and 
Table 5 Number of vaccinated chickens in three project wards

\begin{tabular}{lllll}
\hline Wards & First vaccination & Second vaccination & Third vaccination & Total \\
\hline Mlowa & 17,320 & 25,820 & 21,217 & 64,357 \\
Mzumbe & 27,307 & 30,073 & 31,758 & 89,138 \\
Ufukoni & 850 & 1,700 & 2,298 & 4,848 \\
Total & 45,477 & 57,593 & 34,056 & 158,343 \\
\hline
\end{tabular}

controlling Newcastle and other poultry diseases that devastate the community flock (that intermingles while grazing during the day); although the flock is comprised of individually owned birds. If birds of one owner are infected with ND, they will rapidly infect all the birds of the community. Not surprisingly, the poultry producers of the village communities identify Newcastle disease as the top priority problem hindering the production of free-ranging poultry and they understand the rational for collective action to control it. For this reason, ND prevention was the initial focus of our training efforts and was broadened to include other poultry diseases, once ND control was initiated.

Reviews of community-based health projects have yielded principles and guidance regarding the key characteristics of effective programs (Mansuri and Rao 2004; Catley and Leyland 2001; Riviere-Cinnamond 2005; Scrimshaw and Susan 2006). Generally, success of disease control depends on matching the intervention strategy to the social, economic and ecological conditions of the setting. In these studies, we approached the project communities through their existing social leadership structure and we addressed the locally identified highest priority challenges facing poultry production. From this foundation, our project incorporated several of the factors of success, identified in previous human health community-based programs. We engaged and trained leaders at the district, ward, and village levels, to ensure local leaders were supportive of, if not fully involved in, implementation and supervision of training and delivery of technical information and resources to promote animal health. Village and sub-village leaders and training of household poultry producers were engaged and trained, which fostered collective agreement and action at the village level to prevent poultry diseases where co-mingling of household free-ranging poultry occurs. Community-based vaccinators or suppliers of vaccine and poultry supplies were trained and employed, which engenders community trust and ownership. We trained household poultry-keepers in basic poultry husbandry skills and disease prevention and treatment. We utilized a broad training curriculum with a holistic approach to improving poultry health, production, and marketing.

Our results show that involving the local leadership in the planning and administration of the ND vaccination program was effective in assisting the training of many people and vaccinating many chickens in a short period of time. But beyond these measures of success, new local policies were adopted based on observing preliminary results of increasing chicken numbers in the project villages. Following the first two ND vaccinations, the Veterinary Investigation Centre for the Southern Highlands Zone organized district, ward, and NGO leaders within the zone to utilize district and NGOs resources to adopt an ND vaccination program throughout the area. The zonal program was launched with the declaration of May 5th 2008 as "Kuku Day" (chicken day) to initiate vaccinating chickens in all villages in the zone, which includes the Iringa, Mbeya, Rukwa and Ruvuma regions, covering a total of 24 districts. The coverage and impact of Kuku Day and the zonal ND vaccination program have not yet been appraised, but this action demonstrates a sense of ownership over the project and is a promising indication of the sustainability of the multi-level community approach to poultry health improvement. Beyond the 18-month project period, leaders at all levels agreed to include ND vaccination in their planning and budgeting activities.

This project was designed to take advantage of the established collective action of the village community. The multi-level dimension of the project fully engaged the village leadership prior to training local vaccinators and household poultry producers, instead of taking the more common approach of simply working directly with households (Yongolo et al. 1998). Early engagement of the village and subvillage leaders allowed them to exercise their normal leadership roles of mobilizing the collective action of 
the village residents. The training of local vaccinators and data-recorders contributed to technical capacitybuilding that will remain in the local community after the life of the project.

The village community approach is well-suited to the ecological and social features of rural Tanzania. Ecologically, free-ranging chickens in a sub-village or village are essentially one flock, because they comingle during the day when searching for food. The principles of disease biosecurity necessitate that all of the households whose poultry co-mingle take collective action to prevent diseases in the village flock. Therefore, coordinated community action is imperative to improve the health of all poultry in the village setting.

The vaccination and data recording carried out by local trained personnel was vital in giving the program a local familiar face. Farmers were inclined to interact with the local vaccinators more readily than if vaccinations were carried out by outside project staff or district staff. It is only a question about trust and farmers are more inclined to trust one of their own than a total stranger. Training of farmers as well as vaccinators increased efficiency of the vaccination program because then both parties were familiar with the issues and procedures. However, during the project, farmers were trained last, causing initial difficulties for the vaccinators and recorders working with them. These difficulties included explaining why the farmers had to vaccinate only healthy birds; why birds may die even after vaccination, hence farmers holding the vaccine suspect; and why records must be recorded every week, among other issues. Most of the difficulties encountered by the vaccinators and recorders were significantly reduced after the farmers received training.

The farmers' training also identified the need to give the recorders additional training so that they could respond to village poultry health problems and report them to the extension agents. This cadre of trained recorders made disease identification and reporting effective and efficient. Decentralizing this task to the sub-village level will increase the likelihood that incidences of poultry diseases with high mortality and possible public health implications will be identified and reported early. This is important in the village settings of Tanzania where poultry interact freely with humans, especially children.
Successful programs for human or animal health require an inclusive, holistic strategy. In the setting of local poultry health in Africa, narrow approaches focusing only on ND, or focusing on disease prevention rather than the full range of poultry health and management skills, have had limited success (Yongolo et al. 1998). Other ND vaccination projects have reported early success, but later reported the emergence of other causes of poultry mortality as birds live longer (Yongolo et al. 1998; Kitalyi, personal communications 2006). If farmers do not understand that ND vaccines only protect against ND or are otherwise unprepared for poultry diseases besides ND, confidence in the program falters when other diseases appear. A singular approach to preventing HPAI would likely have even less success while other unaddressed diseases are devastating poultry flocks. Controlling HPAI and ND as part of a more holistic program to prevent poultry diseases in general and improve poultry husbandry has more promise for long-term success (Kitalyi 1998; Oakeley 1999; Alders 2001; Permin et al. 2001).

Novel training methods. We found that novel training methods that avoided traditional lecturestyle presentations were well-received by the communities. In particular, the dramatic presentations delivered to village households were well-received by the audiences, and deemed an effective way to present the material with non-traditional means. Additionally, interaction was encouraged in all courses. During the trainings, most participants shared personal experiences highlighting the importance of chickens for them. Some local leaders were also poultry farmers, and they also participated in these trainings. Farmers indicated that lack of knowledge had been the primary hindrance limiting their ability to improve poultry productivity, and they pledged to use their newly-gained knowledge to improve production. Anecdotally, many trainees told trainers that the most useful part of the training was the briefing on poultry diseases and ways to control them, especially the concept of community disease control.

This project suggests that engaging and training local leaders and farmers, instead of the engaging only government staff or only individual households, will yield more effective and sustainable results for animal health. This kind of multi-level community approach may be practical and effective in many developing countries with grassroots social organiza- 
tions like the village setting in Tanzania. Our project demonstrates that it is particularly important to involve the local leadership during planning and to give them a lead role during implementation of the program. Involving local leaders helps to avoid conflicts with other development programs, especially infrastructural development in the villages. Local leaders can also be of great assistance when setting up schedules for various development activities.

Animal disease control programs in developing countries can be very difficult to implement. In developing countries generally and in Africa specifically, poverty and consequent lack of resources to apply interventions, are critical deficiencies. However, the community structure that exists in many African countries creates an environment for the implementation of community animal disease control programs that is not possible where collective community action is less common. Additionally, the close relationship of people to their sources of food and thus, their recognition of high priority problems like ND in poultry, gave us an opportunity to capture their interest by solving a recognized problem. A poultry disease like ND, which affects community food security, and food security ranks as a high priority in addressing community health.

Social and technical strategies are both very important to the success and sustainability of improving animal health in developing countries. Such strategies that are integrated into the local social structure and addresses local priorities are more likely to succeed.

Acknowledgments This research project was funded by the Global Livestock Collaborative Research Program.

Open Access This article is distributed under the terms of the Creative Commons Attribution Noncommercial License which permits any noncommercial use, distribution, and reproduction in any medium, provided the original author(s) and source are credited.

\section{References}

Alders, R.G. 2001. Sustainable Control of Newcastle disease in Rural Areas. In: Alders, R.G. and Spradbrow, P.B. ed. 2001. SADC Planning Workshop on Newcastle Disease Control in Village Chickens. Proceedings of an International Workshop, Maputo, Mozambique, 6-9 March 2000. ACIAR Proceedings $\mathrm{N}^{\circ} 103$, pp. 80-87.
Alders, R. G., F. dos Anjos, B. Bagnol, A. Fumo, B. Mata and M. Young. 2002. Controlling Newcastle Disease in Village Chickens: A Training Manual. ACIAR Monograph No. 187.

Bajracharya, S.B., P.A. Furley and A.C. Newton. 2006. The impacts of community-based conservation on local communities in the Annapurna Conservation Area, Nepal. Biodiversity and Conservation 15(8): 2765-2786.

Balint, P. 2006. Improving community-based conservation near protected areas: The importance of development variables. Environmental Management 38(1): 137-148.

Banks, T., C. Richard, L. Ping and Y. Zhaoli. 2003. Communitybased grassland management in Western China. Mountain Research and Development 23(2): 132-140.

Barua, A. and Y. Yoshimura. 1997. Rural Poultry Keeping in Bangladesh. World's Poultry Science Journal, 53: 387394.

Beltran D., C. Sandrock, D. Bunn, and C. Cardona. 2008. Avian Flu School: a "train the trainer" approach to prepare for H5N1 highly pathogenic avian influenza. Public Health Reports, 123(3): 323-32.

Bhutta, Z.A., G.L. Darmstadt, B.S. Hasan, and R.A. Haws. 2005. Community-based interventions for improving perinatal and neonatal health outcomes in developing countries: A review of the evidence. Pediatrics, Vol. 115. No. 2. February.

Branckaert, R.D.S. 2007. Avian influenza: the new challenge for family poultry. World's Poultry Science Journal, Vol. 63. $129-131$

Branckaert, R.D.S., Gaviria, L., Jallade, J. and Seiders, R.W. 2000. Transfer of technology in poultry production for developing countries. In: Proceedings of the XXI World's Poultry Congress 20-24, August, Montreal, Canada

Catley, A., and T. Leyland. 2001. Community participation and the delivery of veterinary services in Africa. Preventative Veterinary Medicine, Vol. 49. pp. 95-113.

CLGF (Common Wealth Local Government Forum). 2008. Country profile Tanzania: the local government system in Tanzania. On the web at: http://www.clgf.org.uk/index. cfm/pageid/126/Tanzania, accessed January, 2008.

Curtin, C.G. 2002. Integration of science and community-based conservation in the Mexico/U.S. borderlands. Conservation Biology 16(4): 880-886.

Gubler, D.J. and G.G. Clark. 1996. Community involvement in the control of Aedes aegypti. Acta Tropica, 61: 169-179.

Gueye, E.F. 2000. The role of family poultry in poverty alleviation, food security and the promotion of gender equality in rural Africa. Outlook on Agriculture, Vol. 29, No. 2.

Kitala, P.M., J.J. McDermott, M.N. Kyule and J.M. Gathuma. 2000. Cummunity-based active surveillance for rabies in Machakos District, Kenya. Preventative Veterinary Medicine 44: 73-85.

Kitalyi, A.J. 1998. Village chicken production systems in rural Africa household food security and gender issues. FAO Animal Production and Health Paper 142.

Krishna, A., U. Jonsson and W. Lorri. 1997. The Iringa nutrition project: child survival and development in Tanzania. In A. Krishna, N. Uphoff and M.J. Esman (Eds.) Reasons for hope, instructive experiences in rural development. Kumarian Press. 
Manan, A. and M. Ibrahim. 2003. Community-based river management in Southeast Sulawesi, Indonesia: A case study o the Bau-Bau River. Water Science and Technology 48(7): 181-190.

Mansuri, G. and V. Rao. 2004. Community-based and -Driven Development: A Critical Review. World Bank Policy Research Working Paper 3209.

Minga, U.M., M.M.A. Mtambo, A.M. Katule, S.K. Mutayoba, N.A. Mwalusanya, P. Lawrence, R.H. Mdegela and J.E. Olsen. 2001. Improving the Health and Productivity of the Rural Chicken in Africa: Research and Development Efforts in Tanzania. Proceedings of the SADC Planning Workshop on Newcastle Disease control in village chickens, eds. R .G. Alders and P.B. Spradbrow. Online at www.aciar.gov.au/publication/PR103. Accessed 1/3/09.

Mlozi, M.R.S., A.V.M. Kakengi, U.M. Minga, M.M.A. Mtambo and J.E. Olsen. 2003 Marketing of free-range local chickens in Morogoro and Kilosa urban markets, Tanzania. Livestock Research for Rural Development, 15, 2:2003. http://www. cipav.org.co/lrrd/lrrd15/2/mloz152.htm

Mwaikusa, J.T. 1994. Local Government Policies in Tanzania: The Political Guinea Pig. In Donald Rothchild (Ed.) Strengthening African Local Initiative: Local Self-Governance, Decentralization and Accountability. Institute of African Affairs.

Mwalusanya, N.A., A.M. Katule, S.K. Mutayoba, M.M.A. Mtambo, J.E. Olsen, and U.M. Minga. 2001. Productivity of local chickens under village management conditions. Tropical Animal Health and Production, Vol. 34.

Oakeley, R. 1999. The socio-economic environment of Newcastle disease control strategies for backyard poultry systems. Proceedings of a workshop: Poultry as a tool in poverty eradication and promotion of gender equality. Eds. F Dolberg and P.H. Petersen, March 22-26, 1999. FAO Online: http:// www.fao.org/DOCREP/004/AC154E/AC154E00.HTM.

OECD-DAC (Organization for Economic Co-operation and Development, Development Assistance Committee). 2001. OECD/DAC donor-developing country dialogues on national strategies for sustainable development, country dialogue report for Tanzania. March. Prepared by the Economic Research Bureau, University of Dar es Salaam.

Permin, A. and J.W. Hansen. 1998. Epidemiology, diagnosis and control of poultry parasites. FAO, Rome.

Permin, A., G. Peterson and J.C. Riise. 2001. Poultry as a tool for poverty alleviation: opportunities and problems related to poultry production at the village level. Proceedings of the SADC Planning Workshop on Newcastle Disease control in village chickens, eds. R .G. Alders and P.B. Spradbrow. Online at www.aciar.gov.au/publication/ PR103. Accessed 1/3/09.
Quinn, C.H., M. Huby, H. Kiwasila and J.C. Lovett. 2007. Design principles and common pool resource management: An institutional approach to evaluating community management in semi-arid Tanzania. Journal of Environmental Management 84: 100-113.

Riviere-Cinnamond, A. 2005. Animal health policy and practice: scaling-up community-based aminal health systems, lessons from human health. Pro-Poor Livestock Policy Initiative. Online: PPLPI Working Paper. www.fao. org/ag/againfo/projects/en/pplpi/docarc/wp22.pdf.

Scrimshaw, Susan C. 2006. Culture, Behavior, and Health, in International Public Health, diseases, programs, systems and policies. Eds. m. M.H. Merson, R.E. Black, and A.M. Mills, Publisher: Jones and Bartlett Publishers, 2nd Edition, Chap. 2.

Snyder, K.A. 2008. Building democracy from below: a case from rural Tanzania. Journal of Modern African Studies, Vol. 46 (2), pp. 287-304.

Sonaiya, E.B. (1990). The context and prospects for development of small holder rural poultry production in Africa. In: Proceedings of the CTA Seminar on Small holder Rural Poultry Production 9-13th October, Thessaloniki, Greece volume 1 pp. $35-52$.

Swaddiwudhipong, W., C. Chaovakiratipong, P. Nguntra, S. Koonchote, P. Khumklam, and P. Lerdlukanavonge. 1992. Southeast Asian Journal of Tropical Medicine and Public Health 23(2): 200-206.

Traeger, M., A. Thompson, E. Dickson and A. Provencio. 2006. Bridging Disparity: A multidisciplinary approach for influenza vaccination in an American Indian community. American Journal of Public Health, 96 (5): 921925

Wambura, P. N, A.M. Kapaga and J.M.K. Hyera. 2000. Experimental trials with a thermostable Newcastle disease virus (strain $\mathrm{I}_{2}$ ) in commercial and village chickens in Tanzania. Preventive Veterinary Medicine, 43 (2), 75-83

WHO. 2003. International consultation to review communitybased rehabilitation (CBR), Helsinki, May 25-28.

Yongolo, M.G.S. 1996. Epidemiology of Newcastle disease in village chickens in Tanzania. Unpublished Dissertation for Award of MVM degree at Sokoine University of Agriculture, Morogoro, Tanzania. $230 \mathrm{pp}$.

Yongolo, M.G.S., U.M. Minga, A.M. Katule, M. A. Mtambo, S.K. Mutayoba, R. H. Mdegela and P. Lawrence. 1998. Effect of Newcastle Disease on population and economic impact to scavenging village chicken in Msolwa village in Morogoro Region, Tanzania. In: Proceedings of the Tanzania Veterinary Association scientific conference, Arusha, Tanzania. Pp 90-104. 